Working Paper No. 607, 2003

Search Activities, Cost of Living and Local Labor Markets

by Eleonora Patacchini and Yves Zenou

IUI, The Research Institute of Industrial Economics

P.O. Box 5501

SE-114 85 Stockholm

Sweden 


\title{
Search Activities, Cost of Living and Local Labor Markets
}

\author{
Eleonora Patacchini* \\ Università di Roma "La Sapienza" and University of Southampton \\ Yves Zenou ${ }^{\dagger}$ \\ IUI, University of Southampton and CEPR
}

November 14, 2003

\begin{abstract}
A model is considered in which optimal search intensity is a result of a trade off between short run losses due to higher search costs (more interviews, commuting...) and long-run gains due to a higher chance of finding a job. We show that this optimal search intensity is higher in areas characterized by larger cost of living and/or higher labor market tightness. This model is then tested for England on sub-regional data. We estimate a spatial error model and we find that both the local cost of living and the local labor market tightness are found to have a positive and significant effect on unemployed average search intensity. These findings are consistent with the prediction of the theoretical model.
\end{abstract}

Key words: job matching, search intensities, spatial correlation.

JEL Classification: C21, J64, R1.

${ }^{*}$ University of Southampton, Department of Economics, Southampton SO17 1BJ, UK. E-mail: ep@soton.ac.uk

${ }^{\dagger}$ Corresponding author. Address: IUI, The Research Institute of Industrial Economics, Box 5501, 11485 Stockholm, Sweden. E-mail: yvesz@iui.se 


\section{Introduction}

There seems to be a growing awareness that some patterns of economic variables might be due to spatial rather than purely economic factors. This is particularly true in the labor market (see, for example, Topa, 2001 and Manning, 2003) and more especially for job search activities since a spatial dispersion of agents creates more frictions and thus more unemployment.

The aim of this paper is to investigate, both theoretically and empirically, the relationship between job search and space by focusing on the impact of local cost of living and local labor market tightness on search activities. We believe that the understanding of these relationships is crucial for regional policies.

From a theoretical point of view, few models have introduced a spatial analysis in a search-matching model. Exceptions include Seater (1979), McCormick and Sheppard (1992), Rouwendal (1998), Ortega (2000), Coulson, Laing and Wang (2001), Sato (2001), Wasmer and Zenou (2002), Smith and Zenou (2003). Contrary to these models, our focus is on search intensity and its relationship with cost of living and labor market tightness in a local labor market.

From an empirical point of view, few papers have tested spatial search models. Most of the related empirical literature focuses on the aggregation of the matching function across space and on the interaction between local matching and regional migration or commuting behavior (see in particular the survey by Petrongolo and Pissarides, 2001, and also Jackman and Savouri, 1992, Burda and Profit, 1996, Burgess and Profit, 2001). In the present paper, we analyze a different issue, namely the relationship between the local average job-search intensity, on the one hand, and the local cost of living and/or the local labor market tightness, on the other.

To be more precise, we first develop a simple model in which optimal search intensity is a result of a trade off between short run losses due to higher cost of search effort (more interviews, commuting...) and long-run gains due to higher chance to find a job. We show that this optimal search intensity is higher in areas characterized by larger cost of living and/or higher labor market tightness. The intuition is as follows. When the cost of living increases, workers consume less and thus have more leisure both when they are employed and unemployed. However, because the employed are assumed to value more leisure than the unemployed, the difference in intertemporal utility between the employed and the unemployed increases, and as a result, the unemployed workers search more 
actively because the reward of a successful match is higher. Similarly, when the labor market tightness rises, it becomes easier to find a job (there are relatively more jobs available compared to the unemployed) and thus the returns to search are higher. As a result, workers put more effort in search activities.

Empirical support for this predictions is found in a British panel of subregional data for the year 2000. A spatial lag model is estimated. Once spatial effects and the influence of different area-specific characteristics have been controlled for, both the cost of living and the labor market tightness are found to have a positive and significant effect on the unemployed search intensity.

The remainder of the paper is organized as follows. Section 2 presents the theoretical model and its main predictions. Section 3 describes the data, the empirical models and the estimation results. Finally, Section 4 concludes.

\section{Theoretical model}

We develop a simple model that explains how search effort decisions are made and how cost of living and labor market tightness influence this choice.

Let us first explain the macroeconomic environment. Time is continuous and workers live forever. All workers are ex ante identical. A vacancy can be filled according to a random Poisson process. Similarly, unemployed workers can find a job according to a random Poisson process. In aggregate, these processes imply that there is a number of contacts (or matches) per unit of time between the two sides of the market that are determined by the following standard matching function:

$$
M \equiv M(\bar{s} U, V)
$$

where $U$ and $V$ respectively denote the number of unemployed workers and vacancies. Each unemployed worker $k=1, \ldots, U$ has a search intensity equal to $s_{k}$. Accordingly, $\bar{s}$ represents the average intensity of search of the $U$ unemployed workers. As usual (Pissarides, 2000), $M($.$) is assumed to be increasing$ in both its arguments, concave and exhibits constant returns to scale. As a result, the probability of obtaining a job for an unemployed worker $k$ with search intensity $s_{k}$ is given by:

$$
p\left(s_{k}, \bar{s}, \theta\right) \equiv \frac{s_{k}}{\bar{s} U} M(\bar{s} U, V)=\frac{s_{k}}{\bar{s}} M(\bar{s}, \theta)
$$

where $\theta=V / U$ is the labor market tightness. By using the properties of the matching function, it is easy to see that

$$
\frac{\partial p\left(s_{k}, \bar{s}, \theta\right)}{\partial \theta}>0
$$


since more vacancies in the area increase the probability to find a job whereas more unemployed workers decreases this probability.

Similarly, the probability to fill a vacancy is

$$
q(\bar{s}, \theta) \equiv \frac{M(\bar{s} U, V)}{V}=M\left(\frac{\bar{s}}{\theta}, 1\right)
$$

with

$$
\frac{\partial q(\theta)}{\partial \theta}<0
$$

Equations (3) and (4) express the search externalities that are present in this model. The higher the unemployed who are searching for a job, the easier is to fill a vacancy but the more difficult is to find a job. Similarly, the higher the vacant firms that are searching for a worker, the easier is to find a job but the more difficult is to fill a vacancy.

We now focus on the behavior of an unemployed worker that searches for a job and analyze how this behavior is affected by factors related to his/her residential location, such as living costs and the tightness of the local labor market.

Let us first determine the instantaneous utility function. Let us denote by the superscript ' 0 ' the unemployed group and by the superscript ' 1 ' the employed group. Workers have the following Cobb-Douglas preferences representable by:

$$
V\left(l^{j}, z^{j}\right)=\alpha^{j} \log l^{j}+\left(1-\alpha^{j}\right) \log z^{j} \quad j=0,1
$$

where $0<\alpha^{j}<1$, and $l^{j}$ and $z^{j}$ are respectively leisure and composite good consumptions for workers of type $j=0,1$. We assume that $\alpha^{1}>\alpha^{0}$, which means that, for the same amount of leisure, employed workers value more leisure than unemployed workers or equivalently they value less the composite good consumption $\left(1-\alpha^{1}<1-\alpha^{0}\right)$. This is because working is a more stressful activity than searching and leisure is a scarcer 'resource' for those who are employed. As a result, leisure for the employed (i.e. time spent non working) is more valued than leisure for the unemployed (i.e. time spent non searching). The budget constraint of an employed worker is given by

$$
w T=h z^{1}
$$

where $w$ is the per-hour wage, $h$ is the price of the composite good or equivalently the cost of living and $T$ denotes the amount of working hours. $T$ is assumed to be the same and constant across workers, an assumption that 
agrees with most jobs in the vast majority of developed countries. Each worker provides a fixed amount of labor time $T$. Thus, the time constraint of an employed worker can be written as:

$$
1-T=l^{1}
$$

in which the total amount of time is normalized to 1 without loss of generality. Observe that, since total time is one, $l^{1}$ is the fraction of time spent in leisure.

By plugging (6) and (7) in (5), we obtain the following indirect utility for the employed workers:

$$
V^{1} \equiv V(w, h)=\alpha^{1} \log (1-T)+\left(1-\alpha^{1}\right) \log \left(\frac{w T}{h}\right)
$$

Concerning the unemployed, the utility is given by (5). For an unemployed worker with search intensity $s_{k}$, the budget constraint can be written as

$$
b-C\left(s_{k}\right)=h z_{k}^{0}
$$

where $b$ is the unemployment benefit and $C\left(s_{k}\right)$ is the total cost of searching for jobs. The latter encompasses the costs of buying newspapers, commuting contacting friends, phone calls, interviews... We assume that

$$
C^{\prime}\left(s_{k}\right)>0 \quad, \quad C^{\prime \prime}\left(s_{k}\right)>0
$$

i.e. more search effort implies more search costs and it is even more costly at the margin (convex function). The time constraint is equal to:

$$
l_{k}^{0}+s_{k}=1
$$

In this formulation, the leisure time for unemployed workers is taken to include all time spent not searching for work. Thus, the expected fraction of leisure time for an unemployed worker with search intensity, $s_{k}$, is simply $1-s_{k}$.

By plugging (9) and (11) in (5), we obtain the following indirect utility function for the unemployed with search intensity $s_{k}$ :

$$
V^{0} \equiv V\left(b, h, s_{k}\right)=\alpha^{0} \log \left(1-s_{k}\right)+\left(1-\alpha^{0}\right) \log \left(\frac{b-C\left(s_{k}\right)}{h}\right)
$$

We are now equipped to write $W_{k}^{0}$, the expected discounted lifetime utility of an unemployed worker with search intensity $s_{k}$ and $W^{1}$, the expected discounted lifetime utility of an employed worker (Bellman equation). In steadystate, they are given by:

$$
\begin{aligned}
r W_{k}^{0} & =V^{0}+\frac{s_{k}}{\bar{s}} M(\bar{s}, \theta)\left(W^{1}-W_{k}^{0}\right) \\
& =\alpha^{0} \log \left(1-s_{k}\right)+\left(1-\alpha^{0}\right) \log \left(\frac{b-C\left(s_{k}\right)}{h}\right)+\frac{s_{k}}{\bar{s}} M(\bar{s}, \theta)\left(W^{1}-W_{k}^{0}\right)
\end{aligned}
$$




$$
\begin{aligned}
r W^{1} & =V^{1}-\delta\left(W^{1}-W_{k}^{0}\right) \\
& =\alpha^{1} \log (1-T)+\left(1-\alpha^{1}\right) \log \left(\frac{w T}{h}\right)-\delta\left(W^{1}-W_{k}^{0}\right)
\end{aligned}
$$

where $r \in(0,1)$ is the discount rate and $\delta$ is the job destruction rate. Equation (13) has a standard interpretation. When a worker is unemployed today, he/she obtains an instantaneous (indirect) utility equals to $V^{0}$. Then, he/she can get a job with a probability $\frac{s_{k}}{\bar{s}} M(\bar{s}, \theta)$ and, if so, obtains an increase in utility of $W^{1}-W_{k}^{0}$. Equation (14) has a similar interpretation.

By substracting (14) to (13), we obtain:

$$
W^{1}-W_{k}^{0}=\frac{V^{1}-V^{0}}{r+\delta+M(\bar{s}, \theta) s_{k} / \bar{s}}
$$

Let us now study the search effort decision. When making this decision, the unemployed takes as given the total unemployment level $U$, the total number of vacancies $V$ (and thus $\theta=V / U$ the labor market tightness), the cost of living $h$ and the expected discounted lifetime utilities $W_{k}^{0}$ and $W^{1}$.

By maximizing (13) with respect to $s_{k}$, we obtain ${ }^{1}$

$$
\begin{gathered}
\frac{\partial W_{k}^{0}}{\partial s_{k}}=\frac{\partial V^{0}}{\partial s_{k}^{*}}+\frac{M(\bar{s}, \theta)}{\bar{s}}\left(W_{k}^{1}-W_{k}^{0}\right)=0 \\
\Leftrightarrow \frac{M(\bar{s}, \theta)}{\bar{s}}\left(W_{k}^{1}-W_{k}^{0}\right)=\alpha^{0} \frac{1}{1-s_{k}^{*}}+\left(1-\alpha^{0}\right) \frac{C^{\prime}\left(s_{k}^{*}\right)}{b-C\left(s_{k}^{*}\right)}
\end{gathered}
$$

and where $s_{k}^{*}$ is the unique solution of this maximization problem.

Let us give the intuition of (16). When choosing $s_{k}^{*}$, there is a fundamental trade-off between short-run and long-run benefits for an unemployed worker. On the one hand, increasing search effort $s_{k}$ is costly in the short run (more phone calls, more interviews, less leisure) as it decreases instantaneous utility $\left(\partial V^{0} / \partial s_{k}<0\right)$, but, on the other, it increases the long-run prospects of employment $\left(M(\bar{s}, \theta)\left(W_{k}^{1}-W_{k}^{0}\right) / \bar{s}\right.$ is the marginal return of employment).

At the symmetric equilibrium, all workers provide the same search intensity so that $s_{k}^{*}=s^{*}=\bar{s}^{*}$. Thus, using (15), equation (16) can be written as

$$
\alpha^{0} \frac{1}{1-\bar{s}^{*}}+\left(1-\alpha^{0}\right) \frac{C^{\prime}\left(\bar{s}^{*}\right)}{b-C\left(\bar{s}^{*}\right)}=\frac{M\left(\bar{s}^{*}, \theta\right)}{\bar{s}^{*}} \frac{V^{1}-V^{0}}{r+\delta+M\left(\bar{s}^{*}, \theta\right)}
$$

\footnotetext{
${ }^{1}$ See Lemma 1 in Appendix 1 that shows that there is a unique solution to this maximization problem.
} 
We assume that wages $w$, the number of job created $V$, the unemployment level $U$, and thus $\theta$ are given. ${ }^{2}$ Our main result is as follows:

\section{Proposition 1}

(i) The higher the cost of living $h$, the higher the average search intensity $\bar{s}^{*}=s_{k}^{*}$ of the unemployed workers.

(ii) The higher the labor market tightness $\theta$, i.e. the higher the number of vacancies $V$ or the lower the unemployment level $U$, the higher the average search intensity $\bar{s}^{*}=s_{k}^{*}$ of the unemployed workers.

\section{Proof. See Appendix 1.}

As stated above, when deciding the optimal level of search effort, each unemployed worker trades off the short run losses of increasing effort (higher cost of search effort $C\left(s_{k}\right)$ and less leisure time and thus lower instantaneous utility $V^{0}$ ) with the long-run gains (higher chance to get a job and to enjoy an intertemporal utility difference between employment and unemployment). Proposition 1 analyzes the effect of living costs $h$ (short-run effect) and the one of the labor market tightness $\theta$ (long-run effect) on search effort $s_{k}^{*}$ and average search intensity $\bar{s}^{*}$.

When costs of living $h$ increase, workers reduce their composite consumption both when they are employed and unemployed. However, because the employed value more leisure $\left(\alpha^{1}>\alpha^{0}\right)$ and thus less composite good consumption $\left(1-\alpha^{1}<1-\alpha^{0}\right)$ than the unemployed, the difference in instantaneous utility $V^{1}-V^{0}$ increases since the unemployed are more affected by this increase in $h$ than the employed. Now, because, the marginal intertemporal utility difference between employment and unemployment $\left(W^{1}-W_{k}^{0}\right)$ is equal to the marginal instantaneous utility difference between employment and unemployment $\left(V^{1}-V_{k}^{0}\right)$, i.e.

$$
\frac{\partial\left(W^{1}-W_{k}^{0}\right)}{\partial h}=\frac{\partial\left(V^{1}-V_{k}^{0}\right)}{\partial h}
$$

\footnotetext{
${ }^{2}$ In fact, to endogeneize these variables and to close the model is quite easy since it suffices to add a free entry condition for $\theta$, a wage bargaining determination for $w$ and a steady-state flows in and flows out equation for $U$. This is now standard (Pissarides, 2000). However, the aim of the theory is to shed some light on the relationship between local average search activity and local characteristics by providing a mechanism for the link between $\bar{s}^{*}$ and $h$ and between $\bar{s}^{*}$ and $\theta$, for a given wage and a given unemployment level, that can be easily tested. In the empirical analysis, wages are used as control variables.
} 
an increase in costs of living $h$ raises $W^{1}-W_{k}^{0}$ and, as a result, unemployed workers search more actively because of better returns to search.

Similarly, when the labor market tightness $\theta$ rises, it becomes easier to find a job (there are relatively more jobs available compared to the unemployed) and thus the returns to search are higher. As a result, workers put more effort in search activities.

More generally, the basic message of this model is as follows. If we compare two areas (counties, cities, regions), then, controlling for wages and workers' characteristics, the unemployed workers living either in the more expensive area and/or in the area with the higher labor market tightness, search more on average.

\section{Empirical Analysis}

The aim of this empirical investigation is to test the results of Proposition 1 , namely the positive relationships between $\bar{s}^{*}$ and $h$ and between $\bar{s}^{*}$ and $\theta$. Figure 1 shows three quantile maps that depicts the geographical distribution of the search rate (first panel), the tightness of the local labor markets (panel on the left) and our proxy for costs of living, i.e. house prices, (panel on the right) in England at the NUTS3 level of spatial disaggregation for the year 2000. It appears evident that most of the areas with high (low) levels of local search rate are the areas with high (low) levels of local labor market and cost of living.

Our empirical strategy is to estimate the impact of the local cost of living and the local labor market tightness on the average search intensity, once the influence of other area specific characteristics (skill composition, population structure, economic activity, sectorial composition, quality of the unemployed, income and wealth, ethnic composition, (time) distance to jobs, motor vehicle usage, agglomeration effects, social networks) and spatial effects have been controlled for. 

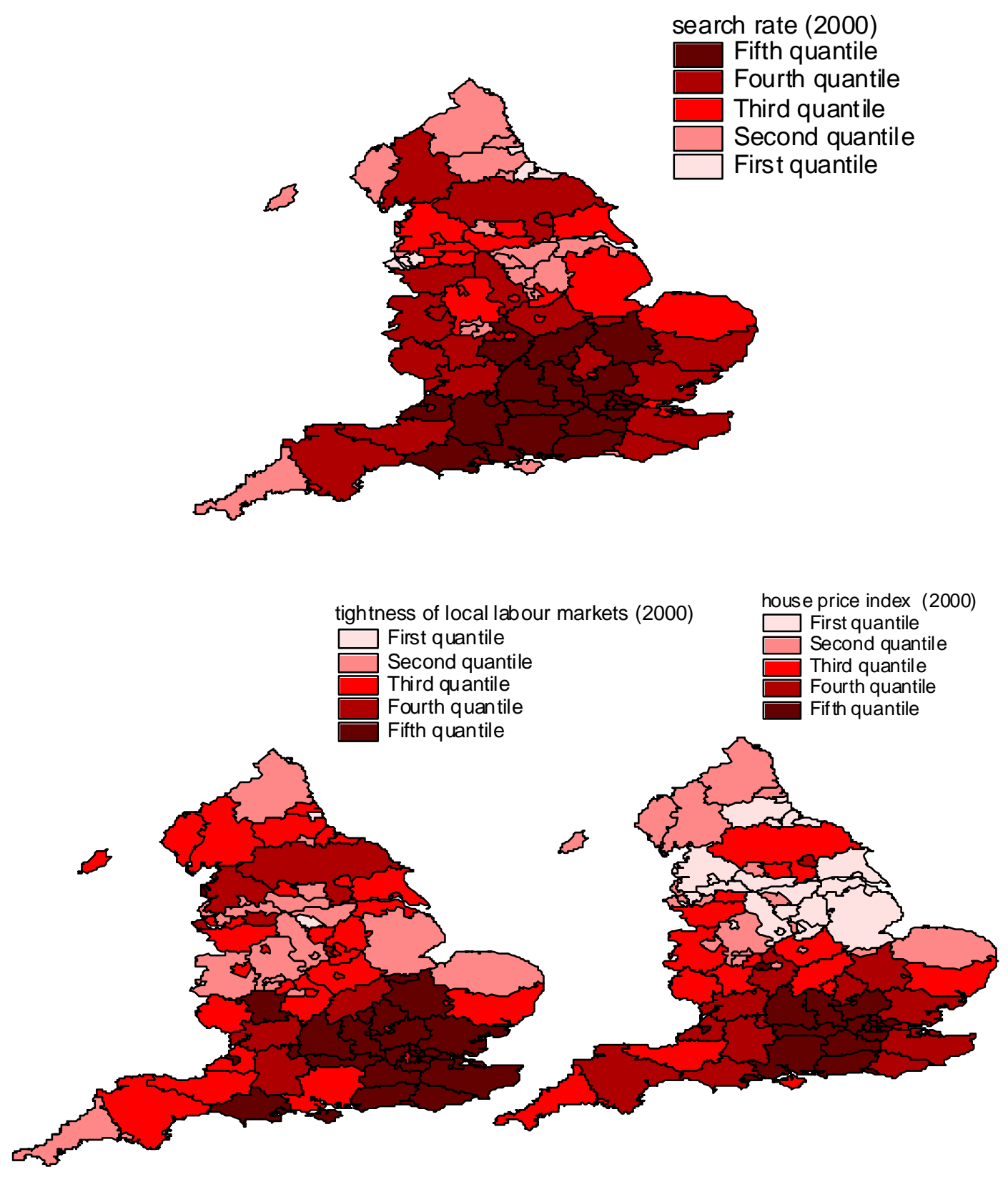

Figure 1: Quantiles maps 


\subsection{Data}

Our empirical analysis is based on NUTS3 level data in England. ${ }^{3}$ The main data source is the Labour Force Survey (LFS hereafter). Given an area, the key variables under investigation are the (average) search intensity, the local cost of living and the local labor market tightness.

We define the average search intensity in area $i, \bar{s}_{i}$, as the ratio between active job seekers, and the sum of active job seekers and inactive persons living in the area. ${ }^{4}$ Observe that, in order to obtain a variable capturing a positive behavior of jobless people in the search process, our definition of active job seekers (the numerator in our measure of local search intensity) includes both the unemployed (these are job seekers who are immediately available for a job) and the persons who declare themselves as job seekers but are currently unavailable to start working (thus defined inactive according to the standard ILO definition of economic activity) for no valid reason.

The other key variable in the theoretical model, the average cost of living in area $i, h_{i}$, is measured by a house price index. We are aware that the interactions between the labor market and the housing market are far more complicated (see e.g. Hughes and McCormick, 2000, Cameron and Muellbauer, 2001). However, because there is no complete set of sub-regional price indices for the UK, the main (and possibly the only) source of variation in prices within regions is differences in house prices. Furthermore, we exclude home-owners so that we rule out the possibility individuals can consider houses as assets.

Finally, the last variable of theoretical interest is the local labor market tightness $\theta_{i}$. The National On-line Manpower Information Service (NOMIS) provides information of the labor market tightness at the county level.

In order to control for differences in skill composition, population structure, economic activity, sectorial composition, income and wealth, ethnic composition, job access, car access, agglomeration effects, social networks among NUTS3 areas, we include as regressors in our empirical model indicators of

\footnotetext{
${ }^{3}$ The Nomenclature of Territorial Units for Statistics (NUTS) was established by the Statistical Office of the European Communities (Eurostat) to provide a single, uniform breakdown of territorial units for the production of Community regional statistics. In Britain, NUTS3 administrative areas are smaller than counties. For example, in the metropolitan area of London, there are five NUTS3 areas.

${ }^{4}$ The ideal variable to measure search effort would have been, at the individual level, the number of hours spent looking for a job. Unfortunately, this variable is not available in any British survey. This is why we resort to our aggregate indicator of search intensity and, as a result, all our empirical analysis will be conducted at an aggregate level (i.e. NUTS3 area).
} 
education, age, economic activity, employment by occupation, indices of earnings by occupation and home ownership, ethnicity, (time) distance to jobs, motor vehicle usage, population density, main method of job search of people living in the area respectively. ${ }^{5}$ For a complete description of all the data, see Appendix 2 .

In order to avoid that differences in earnings across areas are due to the composition of the labor force in the areas, we use a fixed weight index of earnings (where the weights are the share of each occupation in total UK employment). Similarly, in order to avoid that differences in house prices across areas are due to different types of houses being sold in the areas, we also use a fixed weight house prices index (where the weights are the share of each type of houses sales in total UK sales of houses). The construction of both indices is detailed in Appendix 3. Appendix 5 contains the list of the 85 NUTS3 administrative areas considered in the analysis. ${ }^{6}$ Precise definitions of all variables used in the empirical analysis can be found in Appendix 2. Table 1 contains the summary statistics.

\footnotetext{
${ }^{5}$ Because the LFS sub-regional data are made available only starting from spring 2000 and earnings data are only available until year 2000, all variables are year 2000 annual averages. All data can be obtained on line from the NOMIS database run by the University of Durham (on behalf of the Office for National Statistics: http://www.nomisweb.co.uk/) or in the ESRC Data Archive (www.data-archive.ac.uk) with the exception of house prices, that are available on line from the HM Land Registry (http://www.landreg.gov.uk/).

${ }^{6}$ Some NUTS3 areas have been aggregated due to lack of data on some of the variables. Also, all the empirical analysis presented in the paper has been performed excluding London before the housing market is quite peculiar.
} 
Table 1: Descriptive Statistics

\begin{tabular}{|c|c|c|c|c|c|}
\hline Variable & Obs & Mean & Std. Dev. & Min. & Max. \\
\hline $\bar{s}$ & 85 & 0.61 & 0.38 & 0 & 1 \\
\hline$h$ & 85 & 78.99 & 43.7 & 34.6 & 179.89 \\
\hline$\theta$ & 85 & 0.2 & 0.18 & 0.05 & 1.2 \\
\hline $\bar{t}^{*}$ & 85 & 48.9 & 36.5 & 5 & 150 \\
\hline $\bar{c}$ & 85 & 67.8 & 27.79 & 33.76 & 91.06 \\
\hline $\bar{u}$ & 85 & 46.66 & 29.97 & 9.99 & 65.32 \\
\hline$h \_o w$ & 85 & 61 & 20.18 & 10.1 & 92.4 \\
\hline$d$ & 85 & 893.98 & 1409.8 & 14.8 & 9950.01 \\
\hline network & 85 & 58.01 & 7.57 & 9.2 & 72.2 \\
\hline whites & 85 & 84.64 & 8.57 & 75.99 & 98.06 \\
\hline$a$ & 85 & 84.04 & 4.62 & 72.33 & 91.01 \\
\hline skills3+ & 85 & 56.31 & 16.68 & 33.33 & 74.56 \\
\hline$y 16-24$ & 85 & 7.91 & 5.1 & 3.4 & 17.3 \\
\hline$y 25-49$ & 85 & 27.22 & 3.25 & 20 & 37.2 \\
\hline$y 50-64$ & 85 & 49.7 & 4.98 & 22.5 & 69.3 \\
\hline$e \_123$ & 85 & 34.5 & 15.90 & 15 & 49 \\
\hline$e \_67$ & 85 & 72.2 & 16.2 & 43 & 88 \\
\hline e_ 89 & 85 & 60.5 & 29.3 & 25 & 86 \\
\hline$w_{-} 123$ & 85 & 93.88 & 8.51 & 79.17 & 114.50 \\
\hline$w \_45$ & 85 & 97.82 & 7.52 & 87.57 & 115.18 \\
\hline$w \_67$ & 85 & 97.97 & 7.57 & 82.16 & 119.99 \\
\hline$w \_89$ & 85 & 99.61 & 9.07 & 83.36 & 135.52 \\
\hline
\end{tabular}

* This time corresponds to a return trip in minutes.

\subsection{Statistical model and estimation results}

We use a regression model with a spatial autoregressive process for the error term. We write the model by separating the target variables from the other control variables for sake of clarity: ${ }^{7}$

$$
\begin{aligned}
\bar{s} & =\delta h+\gamma \vartheta+X \beta+\varepsilon, \\
\varepsilon & =\lambda P \varepsilon+\xi
\end{aligned}
$$

\footnotetext{
${ }^{7}$ Theoretical details on the spatial error model can be found, among others, in Anselin (1988).
} 
where $\bar{s}, h$ and $\vartheta$ are $N \times 1$ vectors of observations $(N=85$, the number of areas considered) on the search rate, cost of living and labor market tightness respectively, $X$ is a $N \times k$ matrix of observations on the control variables (including a constant term), $\varepsilon$ is a $N \times 1$ vector of normally distributed error terms, $P \varepsilon$ is a $N \times 1$ vector of spatial lags for the errors, that is obtained by setting the elements of the matrix $P, p_{i j}$, equal to 0 if $i=j$ or if $i$ and $j$ are not adjacent, and equal to a constant otherwise (defined by imposing the normalization $\sum_{j=1}^{n} p_{i j}=1$ for each $\left.i\right), \lambda$ is the spatial autoregressive coefficient and $\xi$ is a $N \times 1$ vector of normally distributed random error terms, with means 0 and constant variances $\sigma^{2}{ }^{8}$

The choice of a regression model that controls for spatial dependence is motivated by statistical consideration. Indeed, the estimation of a standard regression model with diagnostics for spatial effects provides strong evidence of the presence of spatial dependence (see Appendix 4 for a detailed analysis on this issue). ${ }^{9}$ Thus, in order to assess correctly the significance of the coefficients of the variables of interest, this spatial dependence cannot be neglected.

On the other hand, the use of a spatial error model instead of a spatial lag model is motivated by economic considerations. Indeed, from a behavioral perspective, it makes little sense to estimate a spatial lag model in the context of our model since it implies that search decisions of workers in different spatial areas are jointly determined. On the other hand, both the theoretical model and its empirical equivalent may miss some determinants of search activity, and if these determinants are correlated across areas, then the spatial error model is appropriate. For example, maybe (unobserved) road congestion deters search, with congestion being high in highly urbanized areas, which may be spatially adjacent, and low in less-urbanized areas, which are also spatially adjacent. ${ }^{10}$

As a result, we estimate the spatial error model (18)-(19). The Maximum Likelihood estimation results (ML) on the target variables are reported in Table 2, second column. ${ }^{11}$ For comparison purpose, the first column of this table display the OLS estimates that are obtained by estimating equation (18) assuming spherical disturbances. A complete statistical analysis of model (18)(19), including estimation results for control variables and hypotheses tests, is

\footnotetext{
${ }^{8}$ The $N \times N$ matrix $P=\left\{p_{i j}\right\}$ is sometimes called contiguity matrix in the spatial statistics literature. It describes the geographical arrangement of the spatial units.

${ }^{9}$ In fact, a feature often neglected in regional studies, where the units have a spatial connotation, is the possible cross-sectional dependence of the residuals.

${ }^{10} \mathrm{We}$ are grateful to Jan Bruecker for providing this example.

${ }^{11}$ For details on the adaptation of the Maximum Likelihood estimator to this spatial case and on the estimation procedure see, among others, Anselin (1988).
} 
contained in Appendix 4. ${ }^{12}$ We conclude that the spatial error model defined by (18)-(19) appears to be appropriate and correctly specified.

Let us now focus on the interpretation of the Maximum Likelihood estimation results (column two of Table 2).

Table 2: Estimation Results - Target variables -

\begin{tabular}{|c|c|c|}
\hline & $\begin{array}{l}\text { OLS } \\
\text { (standard } \\
\text { regression } \\
\text { model) }\end{array}$ & $\begin{array}{l}\text { ML } \\
\text { (spatial er- } \\
\text { ror model) }\end{array}$ \\
\hline cons & $\begin{array}{l}7.453^{* *} \\
(3.7265)\end{array}$ & $\begin{array}{l}5.982^{* *} \\
(2.5029)\end{array}$ \\
\hline$h$ & $\begin{array}{c}0.0889 * * \\
(0.0362)\end{array}$ & $\begin{array}{c}0.0928^{* * *} \\
(0.0311)\end{array}$ \\
\hline$\theta$ & $\begin{array}{c}0.2402^{* * *} \\
(0.076)\end{array}$ & $\begin{array}{c}0.2354^{* * *} \\
(0.0655)\end{array}$ \\
\hline
\end{tabular}

Control variables are included (see Table 4 in Appendix 4 for the complete results)

As predicted by the theoretical model, both the (local) cost of living $h$ and the (local) labor market tightness $\theta$ are found to have a positive and significant effect on unemployed search activity. To be more precise, a unit increase in the cost of living in a county implies an increase of 0.09 in average search intensity in the area $;^{13}$ a unit increase in the average level of labor market tightness $\theta$ increases search effort by $0.24 .^{14}$

\footnotetext{
${ }^{12}$ All the estimation results have been obtained using SpaceStat version 1.80 (Anselin, $1995)$.

${ }^{13}$ Observe that, because the proxy used for (local) living costs is (local) house prices and not an index of all the consumption goods, the effect of the cost of living on search intensity should be smaller. However, since housing constitutes an important part of the household expenses, the difference should not be large.

${ }^{14}$ Different specifications of the empirical model and estimation methods are also been considered. First, in order to control for a potential reverse causality between local search rate and local cost of living this model specification has also been estimated instrumenting the houses prices by taking the historical prices. The first period of the available series, last term of 1998, has been used as instruments. Also, lag values of the labor market tightness have been used as instruments for the values of the variable at time $t$ to account for a
} 


\section{Conclusion}

In this paper, we examine the link between the local search activity of unemployed workers and residential characteristics, namely the local cost of living and local labor market tightness. We first develop a model that shows why areas with large cost of living and/or high labor market tightness are characterized by high levels of search activities. The intuition is quite simple. When the cost of living increases, workers consume less and thus have more leisure both when they are employed and unemployed. However, because the employed are assumed to value more leisure than the unemployed, the difference in intertemporal utility between the employed and the unemployed increases, and as a result, the unemployed workers search more actively because the reward of a successful match is higher. Similarly, when the labor market tightness

possible endogeneity issue. Second to investigate the importance of unobserved heterogeneity between areas and measurement errors in observed variables, we estimated a spatio-temporal model specified as a typical dynamic panel data model. The available data prevent us to perform a panel data analysis using a complete set of controls variables. We use all the nine waves of the BHPS to construct the local search rate and we estimated the following space-time autoregressive model:

$$
\begin{aligned}
\bar{s}_{t} & =\rho \bar{s}_{t-1}^{*}+\lambda P \bar{s}_{t}^{*}+\delta h_{t}^{*}+\gamma \vartheta_{t}+\eta+\varepsilon, \\
\bar{s}_{t}^{*} & =\bar{s}_{t}+m_{t}, \\
h_{t}^{*} & =h_{t}+m_{t}, \quad t=1, \ldots, 9
\end{aligned}
$$

where the same definitions of model (18)-(19) apply, with the difference that $\varepsilon$ is now a white noise disturbance term and as proxy for the cost of living, $h$, the Halifax price index (all data available on line: http://www.hbosplc.com/view/housepriceindex/housepriceindex.asp) has been used, because it is available at sub-regional level for a longer time period. In addition, $\bar{s}_{t-1}$ is the time lag for the search rate, $\eta$ is a vector of time invariant area specific fixed effects, variables denoted by ${ }^{*}$ represent the true latent variables and $m_{t}$ is a measurement error, assumed to follow different stochastic processes. After controlling for spatial dependence in the data by choosing an appropriate order in the spatial process, the literature on dynamic panel data models can be used. The model can be estimated using an instrumental variables approach within a Generalized Method of Moments (GMM) estimation procedure (Arellano and Bond (1991)). Distributional assumptions are not needed. Different specifications for the measurement errors in observed variables can be taken into account by using sufficiently lagged variables as instruments.

For the purpose of this paper, i.e. the empirical test of the theoretical model, the interesting result is that the estimation results related to the target variables (that is positive and significant estimated coefficients of local cost of living and local labor market tightness) remain qualitatively unchanged across all the model specifications and estimation methods used. 
rises, it becomes easier to find a job (there are relatively more jobs available compared to the unemployed) and thus the returns to search are higher. As a result, workers put more effort in search activities.

We then test these predictions on sub-regional data in England for the year 2000 using a spatial lag model. Both the local cost of living and the local labor market tightness are found to have a positive and significant effect on the average unemployed labor market participation. These findings are consistent with the prediction of the theoretical model.

We believe that these results have important implications for regional policies. Indeed, workers seem to search more actively in areas for which both costs of living and labor market tightness are quite high. If we look again at the maps described in Figure 1, then, not surprisingly, in England, these areas are located in the southern part of the country. This suggests that policies that aim at reducing local unemployment should be more active in the North by, for example, subsidizing housing or inducing firms to set up there. This is reinforced by the fact that spatial correlation is quite strong, i.e. high-search intensity areas are in general adjacent to areas with the same characteristics. This suggests that a relevant issue for future research could be to investigate more closely the spatial interdependence between local labor markets.

\section{References}

[1] Anselin, L. (1988), Spatial Econometrics: Methods and Models, Dordrecht: Kluwer Academic Publishers.

[2] Arellano, M. and S. Bond (1991), "Some test of specification for panel data: Monte Carlo evidence and an application to employment equations", Review of Economic Studies, 58, 277-297.

[3] Anselin, L. (1995), SpaceStat Version 1.80. User's Guide, Morgantown: Regional Research Institute, West Virginia University.

[4] Burda, M. and S. Profit (1996), "Matching across space: Evidence on mobility in the Czech Republic", Labour Economics, 3, 255-278.

[5] Burgess, S. and S. Profit (2001), "Externalities in the matching of workers and firms in Britain", Centre for Economic Performance Discussion Paper 490, London School of Economics. 
[6] Cameron, G. and J. Muellbauer (2001), "Earnings, unemployment and housing in Britain", Journal of Applied Econometrics, 16, 203-220.

[7] Cliff, A.D. and J.K. Ord (1973), Spatial Autocorrelation, London: Pion Limited.

[8] Cliff AD. and J.K. Ord. (1981), Spatial Processes: Models and Applications, London: Pion

[9] Coulson, E., Laing, D. and P. Wang (2001), "Spatial mismatch in search equilibrium", Journal of Labor Economics, 19, 949-972.

[10] Hughes, G. and B. McCormick (2000), "Housing policy and labour market performance", Report for DETR, unpublished manuscript, University of Southampton.

[11] Jackman, R.and S. Savouri (1992), "Regional migration in Britain: An analysis of gross flows using NHS central register data", Economic Journal, 102, 1433-1450.

[12] Manning, A. (2003), "The real thin theory: Monopsony in modern labour markets", Labour Economics, 10, 105-131.

[13] McCormick, B. and S. Sheppard (1992), "A model of regional contraction and unemployment", Economic Journal, 102, 366-377.

[14] Ortega, J. (2000), "Pareto-improving immigration in an economy with equilibrium unemployment", Economic Journal, 110, 92-112.

[15] Petrongolo, B. and C.A. Pissarides (2001), "Looking into the black box: a survey of the matching function", Journal of Econmic Literature, 39, 390-431.

[16] Pissarides, C.A. (2000), Equilibrium Unemployment Theory, Cambridge (MA.): The MIT Press.

[17] Rouwendal, J. (1998), "Search theory, spatial labor markets, and commuting", Journal of Urban Economics, 43, 1-22.

[18] Sato, Y. (2001), "Labor heterogeneity in an urban labor market", Journal of Urban Economics, 50, 313-337.

[19] Seater, J. (1979), "Job search and vacancy contacts", American Economic Review, 69, 411-419. 
[20] Smith, T.E. and Y. Zenou (2003), "Spatial mismatch, search effort and urban spatial structure", Journal of Urban Economics, 54, 129-156.

[21] Topa, G. (2001), "Social interactions, local spillovers and unemployment", Review of Economic Studies, 68, 261-295.

[22] Wasmer, E. and Y. Zenou (2002), "Does city structure affect job search and welfare?", Journal of Urban Economics, 51, 515-541. 


\section{Appendix 1: Proofs of propositions}

\section{Proof of Proposition 1}

Before proving this proposition, let us state the following Lemma.

Lemma 1 There exists a unique solution $s_{k}^{*}$ to the first order condition (16).

Proof. By totally differentiating (16), we obtain the following second order condition:

$$
\begin{aligned}
S O C & =\frac{\partial^{2} V^{0}}{\partial s_{k}^{2}}+\frac{M(\bar{s}, \theta)}{\bar{s}} \frac{\partial\left(W^{1}-W_{k}^{0}\right)}{\partial s_{k}} \\
& =-\left(1-\alpha^{0}\right) \frac{C^{\prime \prime}\left(s_{k}\right)\left(b-C\left(s_{k}\right)\right)+\left[C^{\prime}\left(s_{k}\right)\right]^{2}}{\left[b-C\left(s_{k}\right)\right]^{2}}+M(\bar{s}, \theta) \frac{\partial\left(W^{1}-W_{k}^{0}\right)}{\partial s_{k}}
\end{aligned}
$$

Using (15) and (16), it is easy to check that

$$
\frac{\partial\left(W^{1}-W_{k}^{0}\right)}{\partial s_{k}}=0
$$

so that

$$
\begin{aligned}
S O C & =\frac{\partial^{2} V^{0}}{\partial s_{k}^{2}} \\
& =-\alpha^{0} \frac{1}{\left(1-s_{k}\right)^{2}}-\left(1-\alpha^{0}\right) \frac{C^{\prime \prime}\left(s_{k}\right)\left(b-C\left(s_{k}\right)\right)+\left[C^{\prime}\left(s_{k}\right)\right]^{2}}{\left[b-C\left(s_{k}\right)\right]^{2}}
\end{aligned}
$$

Now, because $C^{\prime \prime}\left(s_{k}\right)>0$, all the terms of $S O C$ are negative and thus $S O C<$ 0 .

Let us now prove Proposition 1.

First, observe that, at the symmetric equilibrium where $s_{k}^{*}=\bar{s}^{*},(15)$ is equivalent to

$$
W^{1}-W_{k}^{0}=\frac{V^{1}-V^{0}}{r+\delta+M\left(\bar{s}^{*}, \theta\right)}
$$

with

$$
\begin{gathered}
V^{1}=\alpha^{1} \log (1-T)+\left(1-\alpha^{1}\right) \log \left(\frac{w T}{h}\right) \\
V^{0}=\alpha^{0} \log \left(1-s_{k}\right)+\left(1-\alpha^{0}\right) \log \left(\frac{b-C\left(s_{k}\right)}{h}\right)
\end{gathered}
$$


We have

$$
\begin{gathered}
\frac{\partial\left(W^{1}-W_{k}^{0}\right)}{\partial h}=\frac{1}{h} \frac{\left(\alpha^{1}-\alpha^{0}\right)}{r+\delta+M(\bar{s}, \theta)}>0 \\
\frac{\partial\left(W^{1}-W_{k}^{0}\right)}{\partial \theta}=-\frac{V^{1}-V^{0}}{[r+\delta+M(\bar{s}, \theta)]^{2}} \frac{\partial M(\bar{s}, \theta)}{\partial \theta}<0
\end{gathered}
$$

Let us first prove $(i)$. By totally differentiating (16), we easily obtain:

$$
\frac{\partial s_{k}^{*}}{\partial h}=-\frac{1}{S O C}\left[\frac{M(\bar{s}, \theta)}{\bar{s}} \frac{\partial\left(W^{1}-W_{k}^{0}\right)}{\partial h}\right]
$$

which, by using (20), is equivalent to:

$$
\frac{\partial s_{k}^{*}}{\partial h}=-\frac{1}{S O C}\left[\frac{1}{h} \frac{M(\bar{s}, \theta)}{\bar{s}} \frac{\left(\alpha^{1}-\alpha^{0}\right)}{r+\delta+M(\bar{s}, \theta)}\right]
$$

where $S O C$, the second order condition, is strictly negative by Lemma 1 and $\alpha^{1}>\alpha^{0}$ by assumption. Thus

$$
\frac{\partial s_{k}^{*}}{\partial h}=\frac{\partial \bar{s}^{*}}{\partial h}>0
$$

Let us now prove (ii). By totally differentiating (16) and by using (3), we easily obtain:

$$
\frac{\partial s_{k}^{*}}{\partial \theta}=-\frac{1}{S O C} \frac{1}{\bar{s}}\left[\frac{\partial M(\bar{s}, \theta)}{\partial \theta}\left(W^{1}-W_{k}^{0}\right)+M(\bar{s}, \theta) \frac{\partial\left(W^{1}-W_{k}^{0}\right)}{\partial \theta}\right]
$$

The sign of $\frac{\partial s_{k}^{*}}{\partial \theta}$ is thus the same as the sign of

$$
\frac{\partial M(\bar{s}, \theta)}{\partial \theta}\left(W^{1}-W_{k}^{0}\right)+M(\bar{s}, \theta) \frac{\partial\left(W^{1}-W_{k}^{0}\right)}{\partial \theta}
$$

By using (21), we have:

$$
\begin{aligned}
& \frac{\partial M(\bar{s}, \theta)}{\partial \theta}\left(W^{1}-W_{k}^{0}\right)+M(\bar{s}, \theta) \frac{\partial\left(W^{1}-W_{k}^{0}\right)}{\partial \theta} \\
= & \frac{\partial M(\bar{s}, \theta)}{\partial \theta}\left(W^{1}-W_{k}^{0}\right)-M(\bar{s}, \theta) \frac{V^{1}-V^{0}}{[r+\delta+M(\bar{s}, \theta)]^{2}} \frac{\partial M(\bar{s}, \theta)}{\partial \theta} \\
= & \frac{\partial M(\bar{s}, \theta)}{\partial \theta}\left[\frac{V^{1}-V^{0}}{r+\delta+M(\bar{s}, \theta)}-M(\bar{s}, \theta) \frac{V^{1}-V^{0}}{[r+\delta+M(\bar{s}, \theta)]^{2}}\right] \\
= & \frac{\partial M(\bar{s}, \theta)}{\partial \theta} \frac{V^{1}-V^{0}}{r+\delta+M(\bar{s}, \theta)}\left[\frac{r+\delta}{r+\delta+M(\bar{s}, \theta)}\right]>0
\end{aligned}
$$

As a result

$$
\frac{\partial s_{k}^{*}}{\partial \theta}=\frac{\partial \bar{s}^{*}}{\partial \theta}>0
$$




\section{Appendix 2: Description of variables}

$\bar{s}$ : Ratio between unemployed and job seekers currently unavailable to start working without a valid reason (not home-owners), and unemployed, job seekers currently unavailable and inactive persons (not home-owners). Source: LFS-INECA variable. It is a derived variable which classifies the individual economic activity according to the ILO standard definitions.

$h$ : Index (fixed weight) of house prices (construction detailed in Appendix 3). Source: HM Land Registry.

$\theta$ : Ratio between monthly unfilled vacancies and unemployed. Source: NOMIS.

$\bar{t}$ : Ratio between total time spent travelling to jobs by employed workers, and total number of employed. Source: LFS

$\bar{c}$ : Ratio between active job seekers owning or using a motor vehicle, and total number of active job seekers. Source: LFS.

$\bar{u}$ : Ratio between workers who have been unemployed for more than one year and the total number of unemployed. Source: LFS.

$a$ : ratio between men of working age economically active and men of working age (16-64). Source: LFS (available from NOMIS).

skills3+: ratio between economically active men above NVQ2 (NVQ3, NVQ4 and higher $)^{15}$ and with other qualifications and men of working age economically active. Source: LFS (available from NOMIS).

$y 16$ - 24: Men aged 16-24 over men aged more than 16. Source: LFS (available from NOMIS).

y25 - 49: Men aged 25-49 over men aged more than 16. Source: LFS (available from NOMIS).

y50 - 64: Men aged 50 up to retirement age over men aged more than 16 . Source: LFS (available from NOMIS).

e_123: All in employment working as managers, professional and technical occupations (SOC 1,2,3) ${ }^{16}$ over total number of employed. Source: LFS

\footnotetext{
${ }^{15}$ The NVQs are levels of vocational qualifications based on statements of performance standards which describe what competent people in a particular occupation are expected to be able to do. They are organised into five levels. For precise definitions see http://www.dfes.gov.uk/nvq/.

${ }^{16}$ The Standard Occupational Classification (SOC) system, developed by the US Department of Labor classifies workers into occupational categories. Each broad occupation includes detailed occupations requiring similar job duties, skills, education, or experience (further details in http://www.bls.gov/soc/home.htm). We use the classification into 9 major groups adopted by our data-source NOMIS.
} 
(available from NOMIS).

e_67: All in employment working as personal service, sales and customer service occupations (SOC 6,7) over total number of employed. Source: LFS (available from NOMIS).

e_89: All in employment working as process, plant and machine operatives and other elementary occupations (SOC 8,9) over total number of employed. Source: LFS (available from NOMIS).

whites :White men aged more than 16 over total men aged more than 16 . Source: LFS (available from NOMIS).

network: Men job seekers of working age that use friends and relatives as main method of job search over total number of men job seekers of working age. Source: LFS (available from NOMIS).

$h \_$ow: Persons home owners over persons aged more than 16 . Source: LFS.

$w_{\text {_ }}$ 123: Index (fixed weight) of earnings for managers, professional and technical occupations (SOC 1,2,3) (construction detailed in Appendix 3). Source: New Earnings Survey (available from NOMIS).

w_45: Index (fixed weight) of earnings for administrative, secretarial occupations and skilled trades (SOC 4, 5) (construction detailed in Appendix 3). Source: New Earnings Survey (available from NOMIS).

$w$ 67: Index (fixed weight) of earnings for personal service, sales and customer service occupations (SOC 6, 7) (construction detailed in Appendix 3). Source: New Earnings Survey (available from NOMIS).

$w_{\text {_ }}$ 89: Index (fixed weight) of earnings for process, plant and machine operatives and other elementary occupations (SOC 8, 9) (construction detailed in Appendix 3). Source: New Earnings Survey (available from NOMIS).

$d$ : Density: ratio of residents over squared hectometers. Variable taken from the 1991 Census database and updated using the Midyear Population Estimates. Source: NOMIS. 


\section{Appendix 3: Index (fixed weight) of earnings and house prices}

We consider four indices of earnings (listed in Appendix 2) that are based on the major groups of the Standard Occupational Classification (SOC2000). They are constructed as follow.

Index (fixed weight) of earnings for area $i$ and group $q$ :

$$
I_{i q}=\frac{\sum_{j=1}^{Q} w_{i j} \bar{\eta}_{j}}{\sum_{j=1}^{Q} w_{U K j} \eta_{U K j}}, \quad q=1, \ldots, 4
$$

where $Q$ is the number of occupational sub-groups $j$ in each group $q$, and

$$
\bar{\eta}_{j}=\frac{\eta_{U K j}}{\eta_{U K}}
$$

$$
\begin{aligned}
\eta_{U K j} & =\text { employed in sub group } j \text { in } \mathrm{UK}, \\
\eta_{U K} & =\text { total employed in } \mathrm{UK}, \\
w_{i j} & =\text { average hourly wage of employed in sub group } j \text { in area } i, \\
w_{U K j} & =\text { average hourly wage of employed in sub group } j \text { in UK. }
\end{aligned}
$$

Similarly, the house price index is constructed as follow.

Index (fixed weight) of house prices for area $i$ :

$$
I_{i}=\frac{\sum_{j=1}^{Q} P_{i j} \bar{\eta}_{j}}{\sum_{j=1}^{Q} P_{U K j} \eta_{U K j}}
$$

where $Q$ is the number of types of houses (detached, semidetached, terrace), and

$$
\begin{gathered}
\bar{\eta}_{j}=\frac{\eta_{U K j}}{\eta_{U K}} \\
\eta_{U K j}=\text { sales of houses of type } j \text { in UK, } \\
\eta_{U K}=\text { total sales of houses in UK, } \\
P_{i j}=\text { average price of houses of type } j \text { in area } i, \\
P_{U K j}=\text { average price of houses of type } j \text { in UK. }
\end{gathered}
$$




\section{Appendix 4: Regression diagnostics}

In this appendix we provide evidence that the statistical models defined by (18)-(19) is appropriate and correctly specified, and the complete list of estimation results.

Let us consider Table 3. It has the same structure than Table 2 (results for the spatial error model in the second column and for the classical regression model in column one) and it reports measures of fit and hypotheses tests. The first row reports the maximized log likelihood (LIK) and the second and third row contain two likelihood based measures of goodness of fit: Akaike Information Criteria (AIC) and Schwartz Criterion (SC). A range of specification diagnostics follows. When estimating a classical regression model (column one and three), it consists of the Jarque-Bera test against non-normality $\left(T_{1}\right)$, the Breusch-Pagan test against heteroskedasticity $\left(T_{2}\right)$, a Lagrange Multiplier test on remaining spatial error autocorrelation $\left(T_{3}\right)$ and a Lagrange Multiplier test on the spatial autoregressive coefficient $\left(T_{4}\right)$. When estimating a spatial error model (column two and four), obviously we do not find the statistic $T_{1}$ (normality is assumed) and $T_{4}$ (there is no spatially lagged dependent variable included in the model specification), there is still a Breush-Pagan test against heteroskedasticity $\left(T_{2}\right)$ and a test on the spatial error autoregressive coefficient $\left(T_{3}\right)$, which is a Likelihood Ratio test in this case. In addition, we also find a Likelihood Ratio test $\left(T_{5}\right)$ and a Wald test $\left(T_{6}\right)$ on the common factor hypothesis. These last two tests verify if the coefficients satisfy the restrictions needed to guarantee the consistency of the spatial error specification. All the statistics are asymptotically distributed as a chi-squared. They differ in terms of degrees of freedom. The $T_{1}$ statistic presents two degree of freedom, both $T_{3}$ and $T_{4}$ statistics have one degree of freedom and $T_{2}, T_{5}$ and $T_{6}$ have as many degrees of freedom as the number of regressors in the model. ${ }^{17}$

Let us focus our attention on the analysis of the specification of model (18)(19). Looking at the diagnostics in column one (classical regression model), the hypothesis of normality of the errors cannot be rejected (the $T_{1}$ statistic is not significant). This implies that the other misspecification tests (various Lagrange multiplier tests), that depend on the normality assumption, can be safely used. The $T_{2}$ statistic is not significant, providing no evidence of heteroskedasticity. On the contrary, both tests for spatial dependence $\left(T_{3}\right.$ and $\left.T_{4}\right)$

\footnotetext{
${ }^{17}$ For more details and a technical discussion of model validation in spatial regression models (measures of fit and specification diagnostics), see Anselin (1995).
} 
are highly significant, indicating clearly the presence of spatial dependence ignored in the model. Although the $T_{4}$ statistic is slightly more significant than the $T_{3}$ statistic, there is no clear indication to conclude which is the proper alternative spatial model to use (spatial lag model or spatial error model). ${ }^{18}$ As discussed in Section 3.2, we choose the spatial-error model on the basis of economic considerations.

Looking at column two (spatial error model), we can observe that the performance of the spatial model has been improved with respect to the standard regression model (column one) and it appears correctly specified. In fact, if we compare the values of LIK, AIC and SC for this spatial model with the ones reported in the first column (standard regression model), we can observe an increase in the value of LIK and a decrease in the value of AIC and SIC. This is consistent with an evidence that the fit of the model has been improved. Furthermore, the $T_{2}$ statistic is still not significant, providing evidence that there is no ignored heteroskedasticity in the model, the $T_{3}$ statistic is highly significant and neither $T_{5}$ nor $T_{6}$ are significant, indicating that the spatial error specification is appropriate.

If we compare the parameters estimates and associated standard errors in column one and two of Table 2 (i.e. OLS of the standard regression model and ML of the spatial error model), the point estimates are similar but there is a gain in precision of the estimated coefficients using a spatial error model. ${ }^{19}$

For completeness, Table 4 contains the estimation results for the control variables. Quite intuitively, the search behavior of job seekers living in an area appear to be positively and significantly affected by the activity rate, the percentage of young people and negatively and significantly by the percentage of old people and by the percentage of long-term unemployed in the area. Interestingly, we also find that having access to a private motor vehicle has a positive and significant effect on search intensity and that, on the other hand, (time) distance to jobs has a negative and significant effect. These findings suggest an important role of transport mode in shaping job seekers search effort decisions.

\footnotetext{
${ }^{18}$ Note that they are asymptotic tests whereas we deal with a small data set.

${ }^{19}$ Note that the consequences of ignoring spatial error dependence are not severe. OLS estimators are still unbiased. However, they are inefficient. Indeed, also using OLS estimators our our main results, i.e. the positive and significant effect of cost of living and labor market tightness on search intensity are qualitatively the same. The spatial error model has been estimated mainly for robustness check.
} 
Table 3: Measures of fit and Hypotheses tests

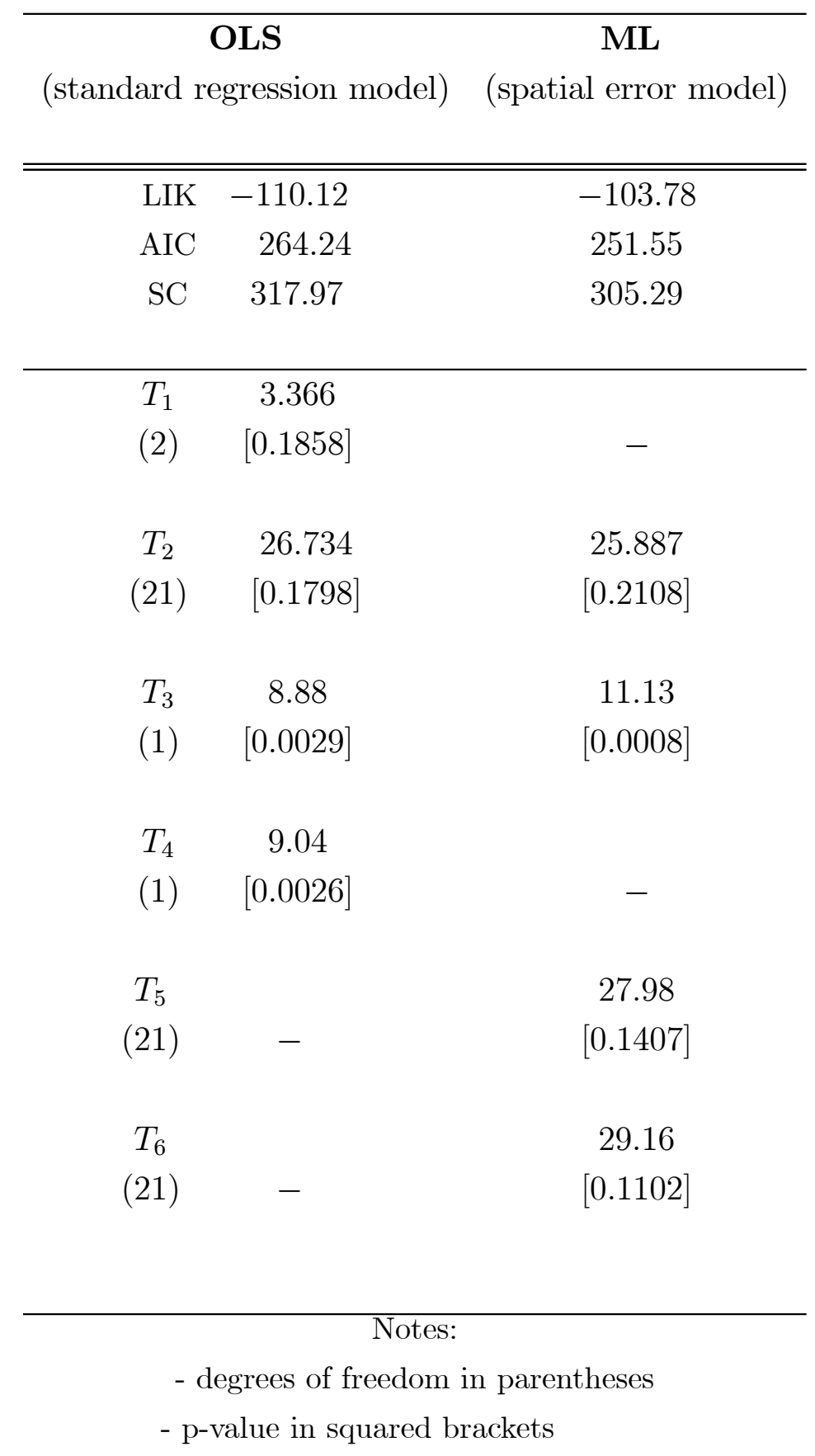


Table 4: Estimation Results -complete model-

\begin{tabular}{|c|c|c|}
\hline & $\begin{array}{c}\text { OLS } \\
\text { (standard regression model) }\end{array}$ & $\begin{array}{c}\text { ML } \\
\text { (spatial error model) }\end{array}$ \\
\hline \multirow{2}{*}{ cons } & $7.453^{* *}$ & $5.982^{* *}$ \\
\hline & $(3.7265)$ & $(2.5029)$ \\
\hline \multirow{2}{*}{$h$} & $0.0889^{* *}$ & $0.0928 * * *$ \\
\hline & $(0.0362)$ & $(0.0311)$ \\
\hline \multirow{2}{*}{$\theta$} & $0.2402^{* * *}$ & $0.2354^{* * *}$ \\
\hline & $(0.076)$ & $(0.0655)$ \\
\hline \multirow{2}{*}{$\bar{t}$} & $0.0063^{* *}$ & $0.0071^{* *}$ \\
\hline & $(0.0027)$ & $(0.0028)$ \\
\hline \multirow{2}{*}{$\bar{c}$} & $0.0579 * *$ & $0.0675^{* * *}$ \\
\hline & $(0.0274)$ & $(0.0232)$ \\
\hline \multirow{2}{*}{$\bar{u}$} & $-0.0746^{* *}$ & $-0.0829 * * *$ \\
\hline & $(0.0337)$ & $(0.0297)$ \\
\hline \multirow{2}{*}{ skills3+ } & -0.0336 & -0.0268 \\
\hline & $(0.9542)$ & $(0.9143)$ \\
\hline \multirow{2}{*}{$a$} & $0.3232^{* *}$ & $0.3825^{* *}$ \\
\hline & $(0.1524)$ & $(0.1567)$ \\
\hline \multirow{2}{*}{$y 16-24$} & $0.5561^{* *}$ & $0.5442^{* *}$ \\
\hline & $(0.2386)$ & $(0.2203)$ \\
\hline \multirow{2}{*}{$y 25-49$} & 0.5471 & 0.4561 \\
\hline & $(1.339)$ & $(1.3227)$ \\
\hline \multirow{2}{*}{$y 50-64$} & $-0.1017^{*}$ & $-0.1402^{* *}$ \\
\hline & $(0.0538)$ & $(0.0631)$ \\
\hline \multirow{2}{*}{$e \_123$} & 0.9411 & 0.8641 \\
\hline & $(0.8933)$ & $(0.8532)$ \\
\hline \multirow{2}{*}{ e_67 } & -0.0254 & -0.017 \\
\hline & $(0.0288)$ & $(0.0208)$ \\
\hline \multirow{2}{*}{$e_{-} 89$} & 0.0435 & 0.0413 \\
\hline & $(0.1671)$ & $(0.1452)$ \\
\hline \multirow{2}{*}{ whites } & 0.092 & 0.1002 \\
\hline & $(0.0663)$ & $(0.0701)$ \\
\hline \multirow{2}{*}{ network } & 0.0102 & 0.0224 \\
\hline & $(0.0995)$ & $(0.0951)$ \\
\hline
\end{tabular}




\begin{tabular}{ccc}
$w_{-} 123$ & -0.0101 & -0.0062 \\
& $(0.0226)$ & $(0.0227)$ \\
$w_{-} 45$ & 0.0065 & 0.0098 \\
& $(0.0169)$ & $(0.0116)$ \\
$w \_67$ & 0.0011 & 0.002 \\
& $(0.0087)$ & $(0.0083)$ \\
$w_{-} 89$ & 0.001 & 0.0005 \\
& $(0.0231)$ & $(0.0268)$ \\
\multirow{2}{*}{$d$} & 0.0006 & 0.0007 \\
& $(0.0216)$ & $(0.0201)$ \\
$h \_$ow & 0.0724 & 0.0617 \\
& $(0.0972)$ & $(0.0871)$ \\
$\lambda$ & & $0.667 * * *$ \\
& & $(0.1797)$ \\
\hline
\end{tabular}

- *** significant at $1 \%$

- ** significant at 5\%

- * significant at $10 \%$ 


\section{Appendix 5: List of NUTS3 administrative areas}

1 Barnsley, Doncaster and Rotherham

2 Bedfordshire

3 Berkshire

4 Birmingham

5 Blackburn with Darwen

6 Blackpool

7 Bournemouth and Poole

8 Bradford

9 Brighton and Hove

10 Bristol, City of

11 Buckinghamshire

12 Calderdale, Kirklees and Wakefield

13 Cambridgeshire

14 Cheshire

15 Cornwall and Isles of Scilly

16 Coventry

17 Darlington

18 Derby

19 Devon

20 Dorset

21 Dudley and Sandwell

22 Durham

23 Cumbria

24 Derbyshire

25 East Merseyside

26 East Riding of Yorkshire

27 East Sussex

28 Essex

29 Gloucestershire

30 Greater Manchester North

31 Greater Manchester South

32 Halton and Warrington

33 Hampshire

34 Hartlepool and Stockton-on-Tees

35 Herefordshire, County of 
36 Hertfordshire

37 Isle of Wight

38 Kent

39 Kingston upon Hull, City of

40 Lancashire

41 Leeds

42 Leicester

43 Leicestershire and Rutland

44 Lincolnshire

45 Liverpool

46 Luton

47 Medway

48 Milton Keynes

49 Norfolk

50 North and North East Lincolnshire

51 North and North East Somerset, South Gloucestershire

52 Nottinghamshire

53 North Yorkshire

54 Northamptonshire

55 Northumberland

56 Nottingham

57 Telford and Wrekin

58 Oxfordshire

59 Peterborough

60 Plymouth

61 Portsmouth

62 Sefton

63 Sheffield

64 Shropshire

65 Solihull

66 Somerset

67 South Teesside

68 Southampton

69 Southend-on-Sea

70 Staffordshire

71 Stoke-on-Trent

72 Suffolk 
73 Sunderland

74 Surrey

75 Swindon

76 Thurrock

77 Torbay

78 Tyneside

79 Walsall and Wolverhampton

80 Warwickshire

81 West Sussex

82 Wiltshire

83 Wirral

84 Worcestershire

85 York 